\title{
Corrigendum to "Formation of Silver Nanoclusters from a DNA Template Containing Ag(I)-Mediated Base Pairs"
}

\author{
J. Christian Léon, ${ }^{1}$ Linda Stegemann, ${ }^{2}$ Martin Peterlechner, ${ }^{3}$ Stefanie Litau, ${ }^{1}$ \\ Gerhard Wilde, ${ }^{3}$ Cristian A. Strassert, ${ }^{2}$ and Jens Müller (iD ${ }^{1}$ \\ ${ }^{1}$ Institut für Anorganische und Analytische Chemie, Westfälische Wilhelms-Universität Münster, Corrensstraße 28/30, \\ 48149 Münster, Germany \\ ${ }^{2}$ CeNTech, Physikalisches Institut, Westfälische Wilhelms-Universität Münster, Heisenbergstraße 11, 48149 Münster, Germany \\ ${ }^{3}$ Institut für Materialphysik, Westfälische Wilhelms-Universität Münster, Wilhelm-Klemm-Straße 10, 48149 Münster, Germany \\ Correspondence should be addressed to Jens Müller; mueller.j@uni-muenster.de
}

Received 10 May 2018; Accepted 20 May 2018; Published 21 June 2018

Copyright (c) 2018 J. Christian Léon et al. This is an open access article distributed under the Creative Commons Attribution License, which permits unrestricted use, distribution, and reproduction in any medium, provided the original work is properly cited.

In the article titled "Formation of Silver Nanoclusters from a DNA Template Containing Ag(I)-Mediated Base Pairs" [1], there was an error in the sequences of duplex $\mathrm{V}$ in Table 1 , which should be corrected as follows:

TABLE 1: DNA oligonucleotide duplexes and sequences investigated in this study.

\begin{tabular}{lrr}
\hline Duplex & Sequence $^{\text {a }}$ & Sequence number \\
\hline I & $5^{\prime}-\mathrm{d}($ GTT TGT TTG XXX XTG TTT TTT T) & ODN1 \\
& $3^{\prime}-\mathrm{d}$ (CAA ACA AAC XXX XAC AAA AAA A) & ODN2 \\
II & $5^{\prime}-\mathrm{d}($ GTT TGT TTG XXX XXT GTT TTT TT) & ODN3 \\
& $3^{\prime}-\mathrm{d}($ CAA ACA AAC XXX XXA CAA AAA AA) & ODN4 \\
III & $5^{\prime}-\mathrm{d}($ GTT TGT TTG YYY YTG TTT TTT T) & ODN5 \\
& $3^{\prime}-\mathrm{d}$ (CAA ACA AAC YYY YAC AAA AAA A) & ODN6 \\
IV & $5^{\prime}-\mathrm{d}($ GTT TGT TTG YYY YYT GTT TTT TT) & ODN7 \\
& $3^{\prime}-\mathrm{d}($ CAA ACA AAC YYY YYA CAA AAA AA) & ODN8 \\
V & 5'-d(GTT TGT TTG TGT TTT TTT) & ODN9 \\
& $3^{\prime}-\mathrm{d}($ CAA ACA AAC ACA AAA AAA) & ODN10 \\
\hline
\end{tabular}

${ }^{\mathrm{a}} \mathrm{X}=$ imidazole nucleoside; $\mathrm{Y}=2$-methylimidazole nucleoside.

\section{References}

[1] J. Christian Léon, L. Stegemann, M. Peterlechner et al., "Formation of silver nanoclusters from a DNA template containing Ag(I)-mediated base pairs," Bioinorganic Chemistry and Applications, vol. 2016, Article ID 7485125, 9 pages, 2016. 

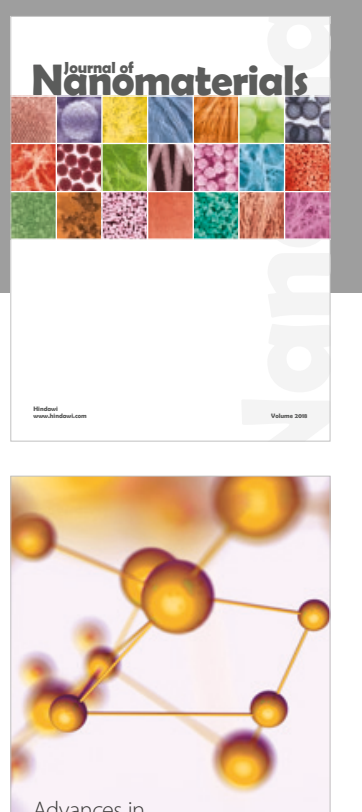

Physical Chemistry
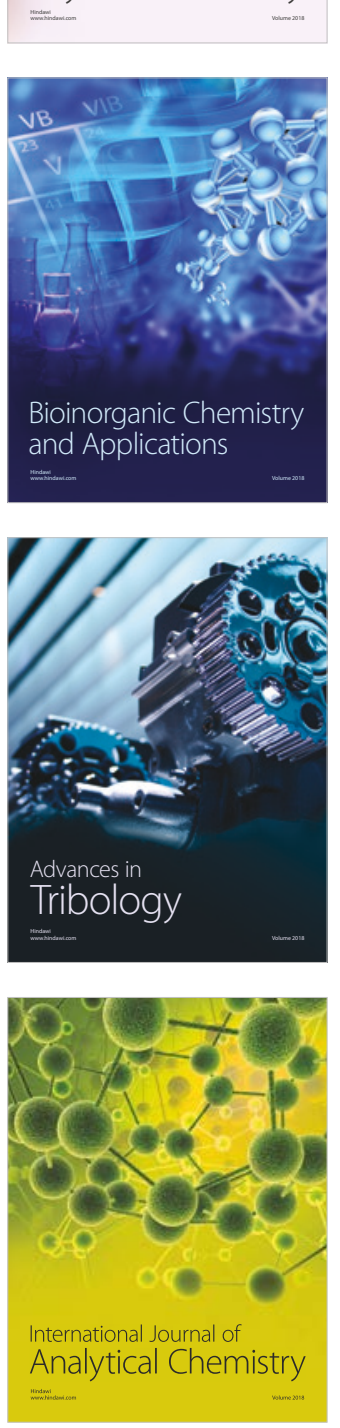

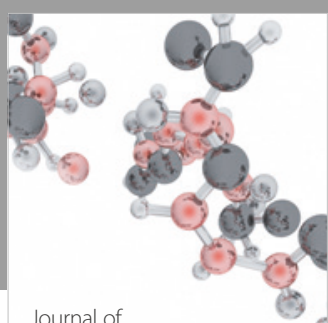

Analytical Methods

in Chemistry

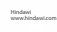

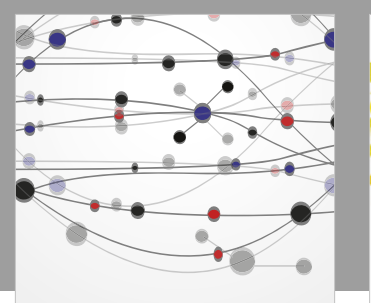

The Scientific World Journal

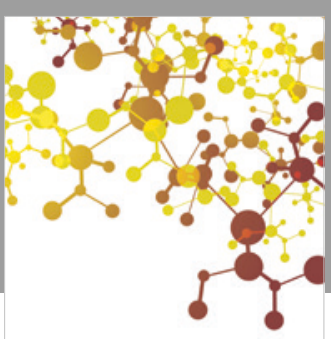

Journal of

Applied Chemistry
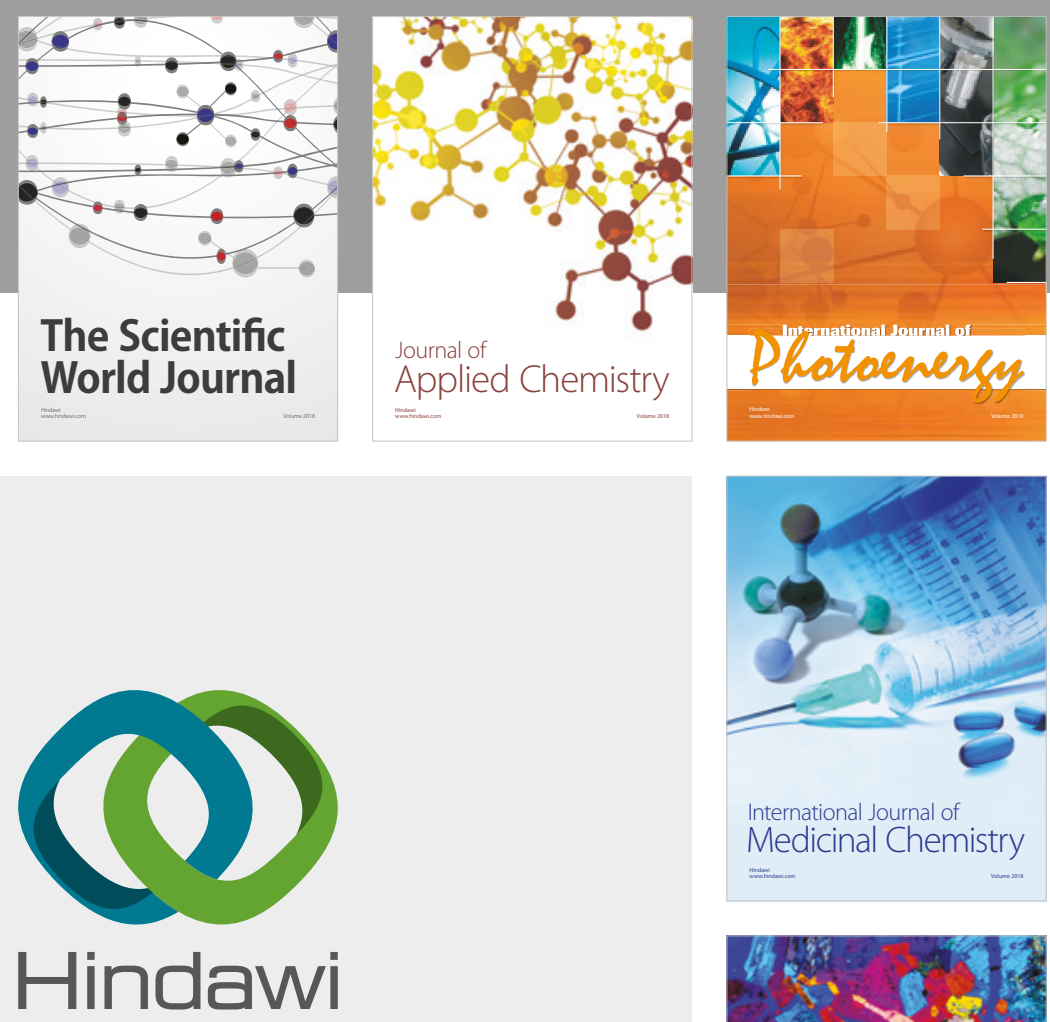

Submit your manuscripts at

www.hindawi.com
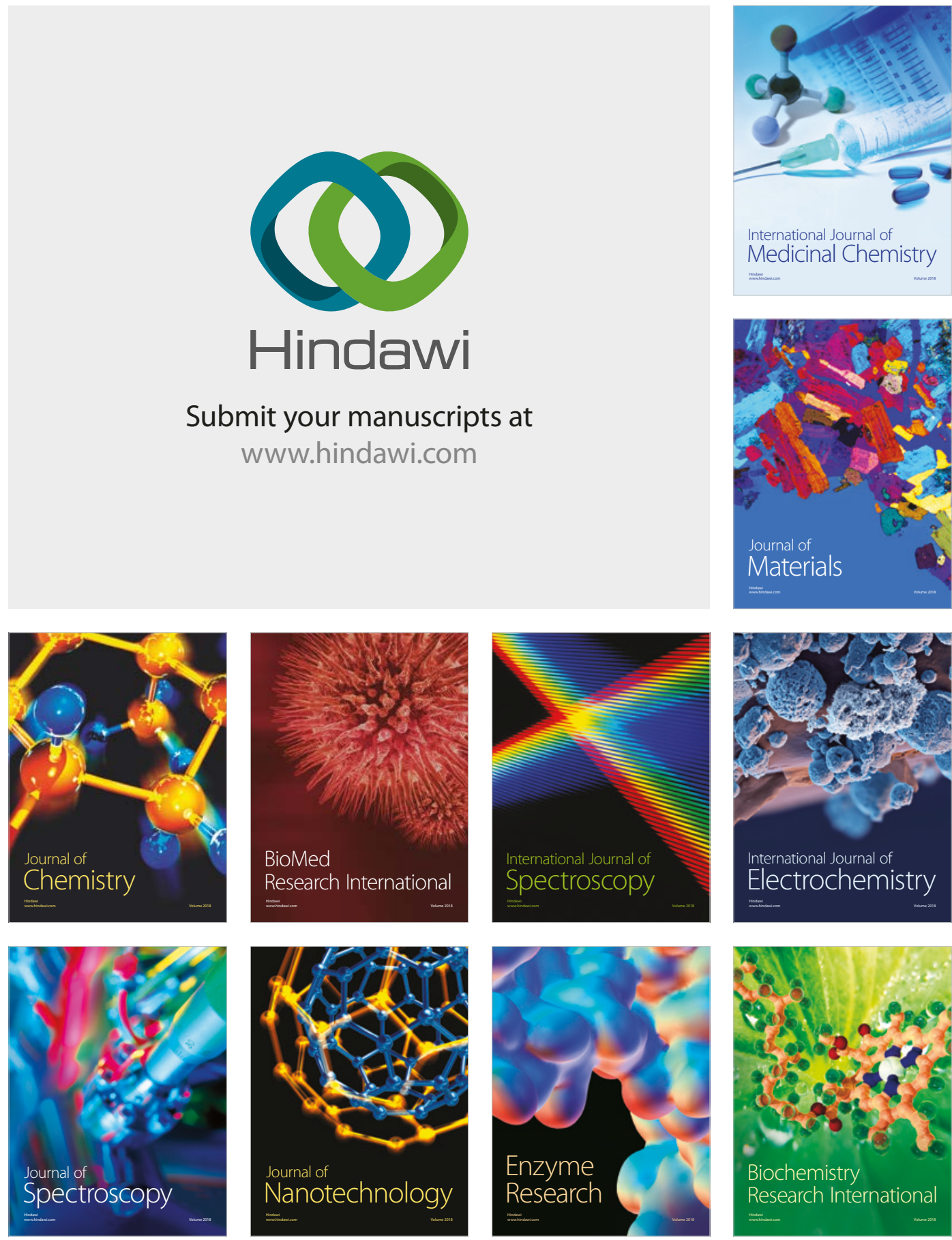
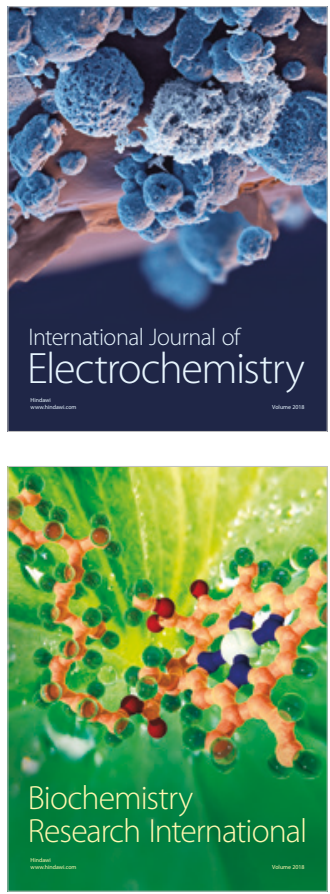